\title{
Sistema de Gestão Integrada na Construção Civil
}

\author{
Integrated Management System in Building Construction Companies
}

\author{
Maria Eduarda Maia Ferreira Gomes ${ }^{1}$ \\ Ana de Fátima Braga Barbosa ${ }^{1}$ \\ ${ }^{1}$ Engenharia Civil. Escola Politécnica da Universidade de Pernambuco \\ E-mail do autor principal: Maria Eduarda Maia Ferreira Gomes maia_mariaeduarda@hotmail.com
}

\section{Resumo}

Um Sistema de Gestão Integrada (SGI) apresenta e incorpora atividades em diversas áreas de uma empresa, a qual busca esforços para a melhoria dos processos, consequentemente, na competitividade do mercado, procurando respeitar as especificações de cada setor, garantindo, assim, a colaboração de todos no desenvolvimento da gestão. $O$ estudo em questão apresenta diretrizes para o planejamento e implementação do SGI em empresas de Construção Civil, descrevendo os processos de Gestão da Qualidade, Responsabilidade Social, Ambiental, Segurança e Saúde no Trabalho, onde se pode observar os diversos aspectos que constituem todo o processo. Apresenta um referencial teórico sobre as características e vantagens da aplicação dos Sistemas de Gestão de maneira integrada, otimizando recursos, processos e melhorando a imagem da organização.

Palavras-Chave: Sistema de Gestão Integrada; Construção Civil; Desenvolvimento da Gestão.

\begin{abstract}
An Integrated Management System (IMS) features and incorporates activities in several areas of a company, which seeks efforts to improve processes, thus the competitiveness of the market, seeking to comply with the specifications of each sector, thus ensuring collaboration all in management development. The study in question provides guidelines for planning and implementation of IMS in building Construction companies, describing the quality management processes, Social Responsibility, Environmental, Occupational Safety and Health, where you can observe the various aspects that make up the whole process. It presents a theoretical framework on the characteristics and advantages of applying an integrated way management systems, optimizing resources, processes and improving the organization's image.
\end{abstract}

Key-words: Integrated Management System; Building Construction Companies; Development Management. 


\section{Introdução}

O mundo em constante processo de transformação faz com que organizações de diversos segmentos e portes tenham que se adaptar às novas tendências do mercado para atender seus consumidores. Atualmente, é comum encontrar empresas buscando certificação na área da qualidade, inclusive no ramo da Construção Civil, um setor deficiente em vários fatores, com grande desperdício de materiais, mão de obra desqualificada e geração de enormes quantidades de resíduos sólidos.

A busca da certificação em Sistemas de Gestão de Qualidade, Meio Ambiente, Saúde e Segurança Ocupacional e Responsabilidade Social cresce a cada dia, seja por exigências do mercado de maneira geral, por consciência social e moral ou pelo conhecimento dos benefícios gerados com a implantação destes sistemas. Para estas empresas, torna-se muito mais vantajosa a implantação desses sistemas de gestão de maneira integrada.

A integração desses diversos sistemas existentes numa empresa é fundamental para a garantia da sua maior competitividade no mercado. Os consumidores cada vez mais esclarecidos tornam-se rigorosos na seleção de produtos e serviços. Valores agregados ao produto tais como marca de conformidade, uso de tecnologia e matéria prima ecologicamente correta, reciclagem após o uso, certificação de qualidade, segurança, responsabilidade social, entre outros, passam a ser requisitos inerentes, considerados pelo consumidor no momento da aquisição.

\subsection{Objetivo Geral}

Apresentar diretrizes para a integração de Sistemas de Gestão da Qualidade, Ambiental, Saúde e Segurança do Trabalho e Responsabilidade Social em empresas do ramo da Construção Civil.

\subsection{Objetivos Específicos}

- Apresentar os conceitos fundamentais de um Sistema de Gestão Integrado;

- Elaborar uma metodologia que aborde a melhoria contínua das etapas de construção de uma obra vertical, referenciando os procedimentos do Sistema de Gestão, de forma integrada, e evidenciando seus benefícios de implantação.

\section{Justificativa}

O mercado da indústria da Construção Civil é caracterizado por instabilidade permanente, 2 vivenciando grandes crescimentos e grandes baixas em períodos curtos e imprecisos. Assim as empresas, para se manterem no mercado, precisam ter muita flexibilidade e, também, solidez estrutural e capital de giro, para absorverem as mudanças rápidas impostas pelo mercado. Neste contexto, os Sistemas de Gestão Integrada quando aplicadas, promovem bons resultados na racionalização dos processos operativos e na otimização da produtividade, fornecendo às empresas as condições básicas necessárias para enfrentarem essas turbulências.

\section{Metodologia}

A metodologia do trabalho envolve uma revisão bibliográfica, com consultas a normas e certificações, a fim de conceituar e desenvolver o tema abordado.

\section{Referencial Teórico}

Define-se como sistema, "um conjunto de elementos dinamicamente relacionados entre si, formando uma atividade que opera sobre entradas e, após processamento, as transforma em saídas, visando sempre atingir um objetivo" [1].

O objetivo dos Sistemas de Gestão de uma empresa é assegurar que seus produtos e seus diversos processos satisfaçam às necessidades dos usuários e as expectativas dos clientes externos e internos. Nesse sentido, o Sistema de Gestão pode ser ilustrado conforme a Figura 1.

Para a implantação do Sistema de Gestão, as empresas utilizam como referencial os requisitos das normas internacionais utilizadas para a certificação dos Sistemas de Gestão. São as normas ISO 9001 para Sistemas de Qualidade, ISO 14001 para Sistemas Ambientais, ISO 16001 para Responsabilidade Social e OHSAS 18001 para Sistemas de Segurança e Saúde no Trabalho.

Segundo o Instituto Nacional de Metrologia, Qualidade e Tecnologia (INMETRO), o setor brasileiro da construção é o terceiro em número de empresas com certificados ISO 9001 credenciados [3]. A normatização da ISO 14001 e da OHSAS 18001, aliada a uma equipe de Serviços Especializados em Engenharia da Segurança e Medicina do Trabalho (SESMT) assegura a saúde, a segurança e o bemestar no meio ambiente de trabalho, garantindo padrões de qualidade e produtividade nas empresas. Uma vez que estes parâmetros trabalham em conjunto, justifica-se a implantação desses sistemas de gestão de maneira integrada. A princípio, como o Sistema de Gestão da Qualidade pela ISO 9001 é o mais difundido na Construção Civil, este pode servir 
de base para a integração com os outros sistemas, como a ISO 14001 e a OHSAS 18001.

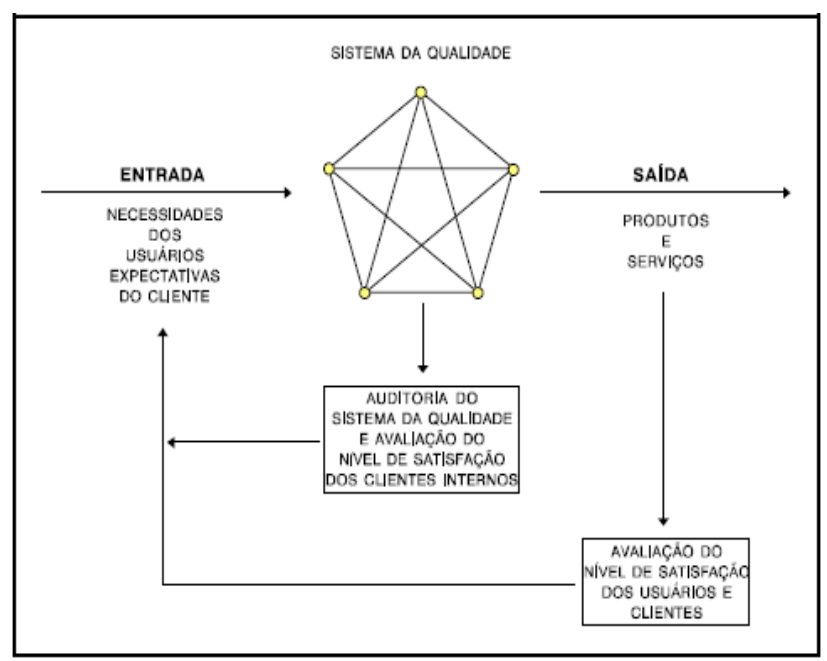

Figura 1: Sistema de Gestão [2]

Dentro desse enfoque sistêmico, as normas internacionais definem o sistema da qualidade como: "estrutura organizacional, responsabilidades, procedimentos, processos e recursos para implementação da gestão da qualidade", ressaltando que o sistema deve ser tão abrangente quanto necessário para atingir os objetivos da qualidade [4]. As vantagens decorrentes dessa abordagem da qualidade permitem à empresa:

- Visão de conjunto: possibilitando um planejamento estratégico, visando a otimização do todo, e não de partes do processo;

- Objetivos comuns: facilitando a compreensão de cada funcionário e departamento do seu papel no todo, tornando mais fácil o trabalho em equipe;

- Integração de áreas: propiciando a combinação de esforços, antes isolados, dos diversos departamentos, obtendo-se sinergia.

O modelo de sistema de gestão da Organização Internacional para Normatização (ISO) requer que seja estabelecida uma política do SGI, cujo objetivo é contemplar as diretrizes da organização em relação aos seus compromissos com a Qualidade, o Meio Ambiente e a Saúde e Segurança no Trabalho. Deve ser adequada ao perfil da organização, considerando a sua natureza, escala e impactos e legislação pertinente. Deve conter o compromisso com a melhoria contínua e a prevenção de impactos adversos, e ser a base para estabelecer os objetivos e as metas da Qualidade, de Meio Ambiente e de Saúde e Segurança no Trabalho.

\subsection{Gestão da Qualidade na Construção Civil}

Os elementos do Sistemas da Qualidade definidos na série de normas NBR ISO 9000 têm aplicação universal. Exatamente por essa razão são genéricos e necessitam de adaptações e maior detalhamento em função do setor em questão.

Particularmente na Construção Civil, que tem tantas especificidades se comparada à indústria propriamente dita, o fundamental de um sistema da qualidade não é seguir rigidamente os tópicos das normas ISO, e, sim, demonstrar o atendimento aos mesmos, desenvolvendo sistemas da qualidade adequados ao setor de construção civil e os mais eficazes quanto possível.

Nesse sentido, o Sistema da Qualidade para Construção Civil deve ser aderente ao ciclo da qualidade do setor, que não é idêntico para todas as empresas construtoras, mas, pode-se afirmar, é muito semelhante. Assim sendo, um Sistema da Qualidade que acompanhe o ciclo da qualidade da construção deve abordar os elementos: A Figura 2 mostra a interligação de cada um desses elementos.

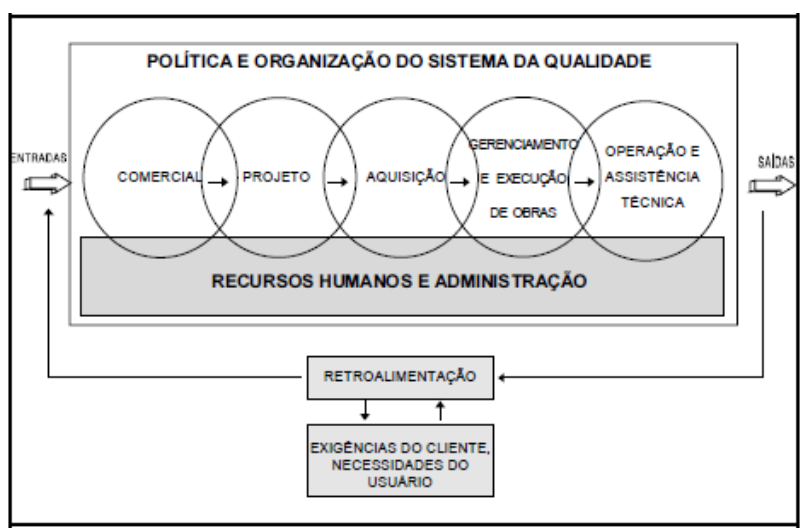

Figura 2: Elementos do Sistema da Qualidade para Empresas Construtoras [4, 2]

- Política e organização do sistema da qualidade;

- Qualidade em recursos humanos e administração;

- Qualidade no processo comercial;

http://dx.doi.org/10.25286/repa.v2i2.542 
- Qualidade na aquisição;

- Qualidade no gerenciamento e execução de obras;

- Qualidade no gerenciamento e execução de obras;

- Qualidade na operação e assistência técnica pós-uso.

Criado em 1998, o Programa Brasileiro da Qualidade e Produtividade do Habitat (PBQP-H) é um instrumento do Governo Federal que tem como objetivo organizar o setor da Construção Civil na busca da melhoria da qualidade do habitat e da modernização produtiva, através da qualificação das Construtoras, aumentando a competividade no setor e a otimização do uso de seus recursos.

Regido pela Portaria N0582, de 5 de dezembro de 2012, O PBQP-H é definido como um Sistema de Gestão da Qualidade específico para a construção civil e segue os princípios da norma ISO 9001. A busca pela qualificação envolve um conjunto de ações, entre as quais se destacam: avaliação da conformidade de empresas de serviços e obras, formação e requalificação de mão-de-obra, normatização técnica, informação ao consumidor e promoção da comunicação entre os setores envolvidos [5].

A adesão ao PBQP-H tem como um dos grandes benefícios, além de propiciar a participação da empresa em licitações com o poder público, a possibilidade de conquista de financiamento em instituições de crédito públicas e privadas, além da participação no programa "Minha Casa, Minha Vida" do Governo Federal. Estes órgãos públicos têm o PBQP-H como pré-requisito para concessão de benefícios.

\subsection{Gestão Ambiental / Responsabilidade Social na Construção}

As organizações de hoje, cada vez mais enfrentam um ambiente dinâmico, convivendo com altas taxas de inovação tecnológica e um elevado nível de competitividade e consequentemente, desafios, tentando manter um ambiente sustentável. Para enfrentar estes desafios, é necessário que se mantenham em permanente melhoria, operando dinamicamente conforme a evolução tecnológica no seu ramo de atividade sem afetar o meio ambiente. Grande parte dessa tecnologia advém das várias áreas da engenharia com as mais variadas técnicas e abordagens para manter 0 desenvolvimento sustentável.

A indústria da construção absorve cerca de $50 \%$ de todos os recursos mundiais [6], daí a grande importância da sua sustentabilidade. Em sua cadeia produtiva, há uma expressiva demanda direta de insumos; são matérias-primas básicas (ferragem, cerâmica, cimento, areia e brita; granito e gesso, tubos e conexões, fios e cabos, olaria, louça sanitária, vidraçaria etc.), equipamentos e serviços de obra. Por estar diretamente associada a aspectos ambientais e socioeconômicos, como consumo de energia, água e matérias-primas, a geração de resíduos, o uso e a ocupação do meio ambiente, a geração de renda, o acesso à moradia digna, entre tantos outros, ela influencia significativamente o nível da qualidade de vida das pessoas.

Construção sustentável significa que os princípios do desenvolvimento sustentável (como por exemplo, o estudo do impacto ambiental da construção no seu entorno, análise do ciclo de vida dos materiais utilizados na obras e aplicação de critérios de sustentabilidade na concepção dos projetos) são aplicados ao ciclo de vida dos empreendimentos que fazem parte do ambiente construído. Este ciclo abrange a extração e beneficiamento da matéria prima, passando pelo planejamento, projeto e construção das edificações e obras de infraestrutura, até a sua demolição e o gerenciamento dos entulhos. $\mathrm{Na}$ preocupação com a sustentabilidade na fase de construção, por exemplo, inserem-se, também, os aspectos relacionados à saúde e segurança ocupacional e à qualidade de vida do trabalhador. Por outro lado, a fase de uso e ocupação - através da análise dos resultados obtidos - oferece a possibilidade de avaliação das decisões de planejamento e de projeto, identificando oportunidades de melhorias para futuros empreendimentos.

O fomento à cultura da sustentabilidade se faz através da sensibilização e da divulgação de conhecimento, capaz de formar opinião junto ao público consumidor, bem como, do investidor público e privado, do projetista e do construtor. Este é um modo seguro, capaz de contribuir para a criação de uma sadia expectativa de mercado, que induza e viabilize novas tendências na arquitetura e engenharia de construção.

\subsection{Saúde e Segurança Ocupacional na Construção}

A indústria da Construção Civil é um dos setores que mais geram emprego. Entretanto, devido à falta de qualificação de seus profissionais e o descaso de algumas empresas é também, um dos setores com o maior número de acidentes e doenças profissionais.

A indústria tem papel importante no Produto Interno Bruto (PIB) da construção, ela responde de 
forma rápida quando medidas econômicas são tomadas de forma correta, toda estrutura da construção emprega 13 milhões de pessoas, considerando empregos formais, informais e indiretos.

Por outro lado, a construção civil lidera o ranking de acidentes de trabalho com mortes no país. De acordo com o Anuário Estatístico do Ministério da Previdência Social, em 2014 foram 54.664 ocorrências, dos quais 36.379 se enquadram como "acidentes típicos", como as quedas em altura - que é a causa mais comum de lesões e morte - e os acidentes em trabalhos de escavação e movimentação de cargas. O Anuário Estatístico da Previdência Social revela que, em 2001, ocorreram no país cerca de 340 mil acidentes de trabalho. Em 2010, o número elevouse para 653 mil e, em 2012, chegou a preocupantes 723 mil ocorrências, dentre as quais foram registrados 2.496 óbitos. Foram quase sete mortes por dia em virtude de acidente de trabalho [7].

A Previdência Social despende, anualmente, cerca de $R \$ 10,7$ bilhões com o pagamento de auxíliodoença, auxílio-acidente e aposentadorias e, segundo o economista José Pastore, o custo total dos acidentes de trabalho é de $\mathrm{R} \$ 71$ bilhões anuais, numa avaliação subestimada [7].

Ao se trabalhar com prevenção, orientando gestores e trabalhadores em questões relacionadas aos procedimentos corretos no processo produtivo, cria-se uma cultura de segurança. A qualidade de vida no ambiente de trabalho reduz drasticamente acidentes e doenças ocupacionais.

A implantação de um Sistema de Gestão Integrado requer mudanças nos conceitos gerais da empresa. Deve haver disposição e participação de todos, especialmente da alta administração, além de uma grande organização das tarefas. Uma vez implantado esse sistema, naturalmente ocorre a mudança na forma de pensar e agir dos atores envolvidos. Um profissional que antes olhava para a obra e via apenas a estrutura de concreto e seus aspectos executivos e de qualidade, passa a olhar para a obra, também, com os olhos de um Engenheiro de Segurança do Trabalho. A partir desse momento, suas preocupações ficam ampliadas, segurança do trabalho passa a ser também uma prioridade. As ações deixam de ser somente corretivas e passam a ser preventivas. 0 profissional passa a atuar como um facilitador na gestão da segurança do trabalho, se antecipando e sensibilizando para o comportamento seguro a todos que encontrar em seu caminho.

\section{Conclusões}

Cada vez mais os aspectos Qualidade, Meio Ambiente, Responsabilidade Social e Segurança e Saúde do Trabalho vêm sendo considerados por consumidores na decisão para a compra de um produto ou a contratação de serviços. Assim sendo, a adoção de técnicas e ferramentas de gerenciamento dessas disciplinas passa a ser estratégica para que as organizações se mantenham no mercado e consigam cumprir seus objetivos e metas rumo à materialização de sua visão de futuro.

Por ser uma questão estratégica, essas três disciplinas não devem ser tratadas independentemente. Precisam fazer parte do planejamento estratégico desenvolvido pela alta direção da organização e de forma integrada. Esse paradigma por si só já é razão suficiente para justificar a adoção do sistema integrado de gestão.

O sistema de gestão não pode ser interpretado como algo a mais que precisa ser feito, e sim, como algo que deve ser feito porque é inerente ao negócio da empresa e às atividades indispensáveis para o seu funcionamento.

No caso da Construção Civil, os elevados índices de acidentes registrados comprovam a necessidade de melhorias na gestão como um todo. Além disso, a construção civil no Brasil apresenta outros fatores desfavoráveis: mão de obra muitas vezes desqualificada; altos índices de desperdício de material e horas trabalhadas; grande geração de resíduos sólidos.

A articulação dos sistemas de gestão aumenta a produtividade, melhora o gerenciamento e potencializa resultados, ao atingir objetivos de forma global e evitar gastos em duplicidade.

\section{Referências}

[1] SOUZA, Roberto (1997). Metodologia para Desenvolvimento e Implantação de Sistemas de Gestão da Qualidade em Empresas Construtoras de Pequeno e Médio Porte. São Paulo, 1997. Tese (Doutorado) - Escola Politécnica, Universidade de São Paulo. Capítulo 2.

[2] Escola Politécnica da Universidade de São Paulo. Departamento de Engenharia de Construção Civil. Gestão na Produção da Construção Civil. Capítulo 2 - Competitividade e Gestão da Qualidade no Setor da Construção Civil. 
Texto de apoio às aulas.

[3] B. Barkokébas, Menos Riscos nos Canteiros. Revista Proteção, N¹83, março 2007.

[4] ABNT, 1994a.

[5] Regimento Geral do Sistema de Avaliação da Conformidade de Empresas de Serviços e Obras da Construção Civil - SiAC, março 2005.

[6] SACHS, I. (2002). Caminhos para o Desenvolvimento Sustentável.

[7] Tribunal Superior do Trabalho. http://www.tst.jus.br/noticias/-

/journal_content/56 